\section{Beyond Stewardship or The Greening of God}

\author{
M. de La Valette \\ South Lynnfield, Massachusetts
}

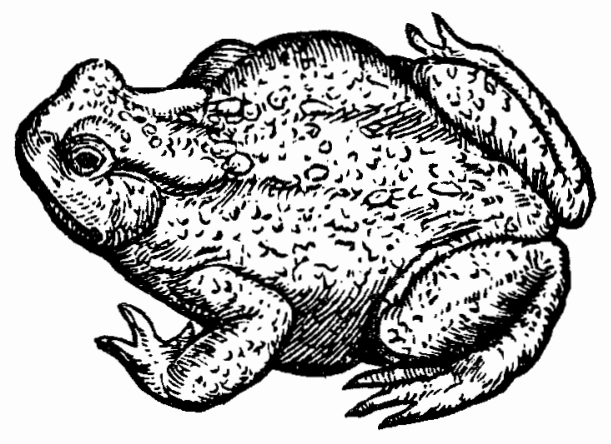

As the inevitable peak and crash syndrome takes shape for the human species, it is interesting to examine the mindset that has led us to the abyss. The population explosion has been fueled in no small way by the biblical injunction to "multiply and replenish" the Earth. We have indeed done that-above and beyond the wildest flights of the imagination. We have adapted to inhabiting the most inhospitable places on the planet-from oxygen-poor mountain tops to the icelocked regions of the Poles, leaving behind us a legacy of depleted and irrevocably damaged ecosystems, and we are now launching into space looking for other planets to colonize.

The myth that has carried us this far, obviously can no longer sustain us. Our Western religions, however, instruct us that our stay on this planet is but a proving ground for the real life to come. Salvation is the name of this politics. In the name of salvation, the many legions of the Pope and the Protestant armies of Calvin, Luther and Knox managed a grand scale takeover of most of Old Europe and the New World, with great success in the Southern hemisphere and inroads into the Orient. Native peoples, attuned to the Earth, were converted and assimilated, or, in more

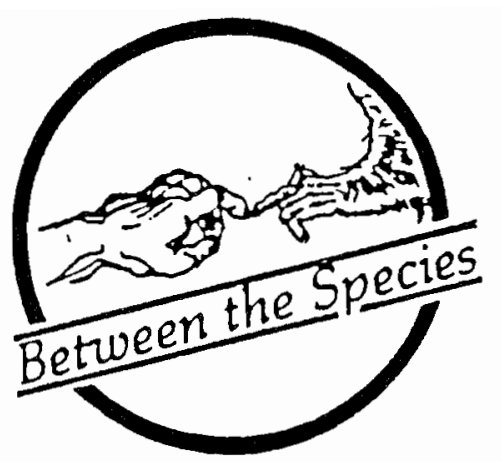

bloody fashion, destroyed in Conquistador type crusades. This salvation-promising, mind-altering 2000 year old campaign created the most powerful empire on Earth, run from the Vatican.

This "opiate of the masses" has been responsible for a truly terrifying list of historical bloodbaths. From the Spanish Inquisition to the burning of witches to the Irish "troubles," more of the Earth's peoples have been divided by religion than by race or culture, and organized religion bears a major share of the responsibility for creating the eco-collapse that we are now facing. Resultingly, many theological scholars are busily attempting yet one more reinterpretation of the book which gave us "dominion" over "all the earth, and over every thing that creepeth upon the earth," "dominion" over "the fish of the sea and the fowl of the air"-a dominion which has permitted and absolved us from the guilt of, the holocaust that we have perpetrated on all living things and on all living systems-a dominion which has sanctioned the wholesale rape of the Earth. This ideology tells us that we are "made in the image of God" and thus, in a divine chain of being, we rest somewhere between the (other) animals and the angels, which gives us the right to use the rest of the lowly life on Earth. Today's theologians are changing the definition of "dominion" to "stewardship" ( Al Gore, an admittedly profoundly "religious" man subscribes to the stewardship concept) This step

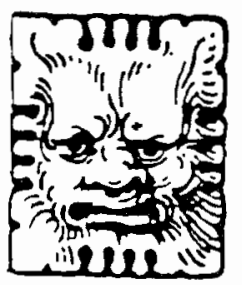


up to stewardship would give us the right to manage the planet-to be the caretakers of this bountiful, beautiful, mysterious Earth. Considering that our knowledge until now has been solely concentrated in turning the Earth's "natural resources" into commodities for trading in order to make some people and some nations rich and powerful, it would appear that we have few references for this kind of job.

At the forefront of this greening of religion is Dean Morton of the Episcopal Cathedral of St. John the Divine. With commissioned Earth Masses, Blessings of the Animals, Recycling programs and other green accoutrements of the New Age, Dean Morton has stated that "Ecology is the Science of the Body of Christ." In remarks introducing Missa Gaia, he asks the question '...how the worship of God by human beings relates to nature and the wider earth community' and finds the answer within '...the Judeo Christian perspective' when the 'Lord of History'... 'placed in human hands and brains both the capacity and the responsibility for the continuing co-creation of the world as partners with God.' Some, in the environmental community, are grateful for these crumbs, others claim that there is scant evidence to support the prospect of a future partnership with God working any better than our past one. The bible has been rewritten and reinterpreted innumerable times, the Essenes, for example, claiming that Jesus was vegetarian and that " 25 miles of bookcases of unpublished manuscripts" at the Vatican contain evidence to totally scrap all editions of the bible to date. The Essenes say that "loaves and fishes" were in actuality "loaves and grapes" and that "meats" were in fact nutmeats. They also state that at the Council of Nicaea in A.D. 325, "correctors" were appointed to rewrite the Gospel of the Holy Twelve to give it wider appeal. So, it is in keeping with history that similar "correcting" is continuing today.

The entire soteriological concept of the Judeo Christian ethic negates the fact of the planet as the source of life. It is merely the host on which we feed in our earthly passage and the underlying assumption of the new stewardship dogina is that we should preserve the Earth in order to continue to exploit it. It is a fanciful vision with no grounding in the fact that the Earth and its "resources" are finite. The concept of (hu)man "made in the image of God" or "co-creator with God" denies the ethic, simply and profoundly stated by Vaclav Havel that “... we are not the pinnacle of evolution, we are merely a part of it." Until theologians reach beyond stewardship to placing the human species in Leopold's words as "...plain member and citizen of the earth community," the holocaust will continue. Until we return to the understanding of all "pagan" peoples that the Earth is the giver of Life and deserves and elicits our adoration, that we, indeed, are part of this Mystery that passes all understanding, we will not halt the head-long rush to the sixth great extinction spasm on Earth.

There is much talk of a new paradigm emerging. What does seem clear is that there is widespread questioning of the value systems we have inherited, and organized religion has been found lacking and no longer serves the public interest. It does not seem possible that organized religion, as we know it, can successfully evolve or change yet one more time to meet the demands of our times, as its very structure and message has brought us to the edge of this precipice.

Paul Ehrlich has written "... we need a quasireligious transformation" to save life on Earth. This may be happening. From the United Nations Environmental Program's Environmental Sabbath to the Unitarian Universalist's Covenant of Unitarian Universalist Pagans to the interest in native American spirituality, large numbers of people are seeking a spiritual dimension to their existence. Leading thinkers such as Arne Naess, Brian Swimme, Alan Drengson, Dolores LaChapelle, Matthew Fox, Starhawk, Lynn Margulis, Carl Sagan, James Lovelock and others have much to contribute to the debate. One New Age concept of humans as "the evolved global brain of the planet" is indicative that we have far to go to shed our arrogance. We would do well to practice humility in our relations with the other more attuned life on Earth.

We have been blinded by various concepts throughout our evolution which have diverted us, as a species, from the grand raison d'etre. Organized religion has done major damage to our development and we do indeed need a revolutionary transformation that will free us from religious bondage and open our eyes to the beauty, wonder and Mystery of this Earth. Life is here and now and not thereafter. All the Debt-for-Nature swaps, Recycling, vegetarianism, negawatts, feebates, Earth Masses, solar power and smart cars, mass transit and population reduction will have only temporary effect until we return to the faith of the First Peoples-That the Earth, Herself, is sacred and is the source of all life; that we should honor Her and adore Her Mystery. 